\title{
JOGO DE DENTRO, JOGO DE FORA: 0 ENCONTRO DE SABERES DA UFRGS E A CAPOEIRA DE MESTRE CHURRASCO
}

\author{
MARCo ANTONIO SARETTA POGLIA ${ }^{1}$ \\ JULIO SOUTO SALOM ${ }^{2}$ \\ MESTRE CHURRASCO 3
}

\begin{abstract}
RESUMO
0 artigo foi elaborado a partir da participação de Mestre Churrasco junto à disciplina Encontro de Saberes na Universidade Federal do Rio Grande do Sul (UFRCS). 0 texto está dividido em duas partes. A primeira constitui um relato do próprio Mestre Churrasco sobre a sua experiência junto à universidade. Na segunda, Marco e Julio, que foram convidados a intermediar a relação com o mestre na disciplina, descrevem os encontros a partir dessa vivência, tentando compreender as formas de articular os saberes em jogo nos encontros.
\end{abstract}

\section{PALAVRAS-CHAVE}

Capoeira; Encontro de Saberes; Mestre Churrasco.

\section{JOGO DE DENTRO, JOGO DE FORA: THE "MEETING OF KNOWLEDGES" OF THE UNIVERSIDADE FEDERAL DO RIO GRANDE DO SUL AND THE CAPOEIRA OF MESTRE CHURRASCO}

\begin{abstract}
The article was prepared based on the participation of Mestre Churrasco in the course "Meeting of Knowledges" at the Universidade Federal do Rio Grande do Sul (UFRGS). The text is divided into two parts. The first constitutes a report by Mestre Churrasco himself about his experience at the university. In the second, Marco and Julio, who were invited to mediate the relationship with the master in the course, describe the meetings from their experience, trying to understand the ways of articulating the knowledges at stake in the meetings.
\end{abstract}

\section{KEYWORDS}

Capoeira; Meeting of Knowledges; Mestre Churrasco.

\section{JOGO DE DENTRO, JOGO DE FORA:"LE "RENCONTRE DE CONNAISSANCES" DE LA UNIVERSIDADE FEDERAL DO RIO GRANDE DO SUL ET LA CAPOEIRA DE MESTRE CHURRASCO}

\footnotetext{
${ }^{1}$ Doutorando em Antropologia (PPGAS/UFRGS), membro do GEAfro - Grupo de Estudos Afro (NEAB/UFRGS) e capoeirista da Áfricanamente Escola de Capoeira Angola. Trabalho realizado com apoio da Coordenação de Aperfeiçoamento de Pessoal de Nível Superior - Brasil (CAPES) - Código de Financiamento 001.

${ }^{2}$ Doutor em Sociologia (UFRGS), capoeirista do grupo Mocambo, professor ESAG/UDESC.

3 Jean Batista Cléber Teixeira Santos. Um dos mais antigos mestres de capoeira do Rio Grande do Sul, fundador da Associação de Capoeira Angola Zumbi do Palmares (ACAZUP).
} 


\title{
RÉSUMÉ
}

L'article a été préparé à partir de la participation de Mestre Churrasco à la discipline "Rencontre de Connaissances" à l'Université Fédérale du do Rio Grande do Sul (UFRGS). Le texte est divisé en deux parties. Dans la première, on trouve un rapport du propre Mestre Churrasco sur son expérience à l'université. Dans la seconde Marco et Julio, invités à médier la relation avec le maître en classe, décrivent les rencontres à partir de cette expérience, essayant de comprendre les manières d'articuler les connaissances en jeu dans les rencontres.

\author{
MOTS CLÉS \\ Capoeira; Rencontre de connaissances; Mestre Churrasco \\ JOGO DE DENTRO, JOGO DE FORA: EL ENCUENTRO DE SABERES DE LA UNIVERSIDADE FEDERAL DO \\ RIO GRANDE DO SUL Y LA CAPOEIRA DE MESTRE CHURRASCO
}

Este artículo fue elaborado a partir de la participación de Mestre Churrasco en el curso "Encuentro del Saberes" de la Universidade Federal do Rio Grande do Sul (UFRGS). El texto se divide en dos partes. La primera constituye un relato del propio Mestre Churrasco sobre su experiencia en la universidad. En el segundo, Marco y Julio, quienes fueron invitados a mediar la relación con el Mestre en las clases, describen los encuentros a partir de esta experiencia, tratando de entender las formas de articular los saberes en juego en los encuentros.

\section{PALABRAS CLAVE}

Capoeira; Encuentro de Saberes; Mestre Churrasco. 


\section{INTRODUÇÃO (MARCO E JULIO)}

No início de 2018, recebemos o convite de uma das professoras organizadoras da disciplina Encontro de Saberes na Universidade Federal do Rio Grande do Sul (UFRGS) para realizarmos o contato e mediação com o Mestre Churrasco para a disciplina, a ocorrer no segundo semestre daquele ano. Meses antes, elas haviam nos consultado sobre a indicação de mestres de capoeira para participar da disciplina e imediatamente indicamos o seu nome. Aceitamos essa tarefa voluntariamente e com muita animação, vinculando-nos institucionalmente à disciplina como estagiários docentes, devido ao apreço que nutrimos pelo mestre e pelo potencial que percebíamos no projeto Encontro de Saberes. Um dos mais antigos mestres de capoeira do Rio Grande do Sul, fundador da Associação de Capoeira Angola Zumbi do Palmares (ACAZUP) e grande referência dessa arte no sul do Brasil, Mestre Churrasco vivenciou a capoeira desde a infância nas ruas de Porto Alegre. Ele é também um grande artífice de instrumentos musicais artesanais, especialmente o berimbau, sendo um profundo conhecedor de madeiras e plantas nativas do estado do Rio Grande do Sul utilizadas para a fabricação dos seus instrumentos.

O programa Encontro de Saberes propõe a incorporação de mestres de ofício e saberes tradicionais aos vários níveis de ensino formal (INCTI, 2015) e vem sendo realizado na UFRGS desde 2016 (STEIN et al. 2019), com alta procura por parte dos estudantes. Como doutorandos da universidade, já havíamos interagido anteriormente com algumas das professoras, que conheciam nossa relação com a capoeira e com o Mestre. A amizade de Marco com ele havia começado há cinco anos, durante a realização do projeto Angola Poa: expressões da capoeira angola em Porto Alegre ${ }^{4}$. Mestre Churrasco é porto-alegrense e atualmente reside em Caxias do Sul (RS), cerca de $100 \mathrm{~km}$ da capital.

Nossa ideia inicial sobre a escrita deste artigo envolvia a proposta de uma escrita em coautoria com Mestre Churrasco, a qual foi preciso abdicar devido ao isolamento social imposto pela pandemia. Assim, elaboramos uma primeira descrição dos encontros a partir da nossa experiência de mediação e convidamos o mestre para fazer um relato livre sobre sua experiência junto à universidade - o que ele já havia manifestado interesse em fazer - para compor o texto ${ }^{5}$. Assim, Mestre Churrasco escreveu um relato de próprio punho, em sua residência, na cidade de Caxias do Sul, o qual foi fotografado pelo seu filho e enviado a nós por Whatsapp. Logo após, o mestre realizou uma ligação telefônica, que foi gravada, na qual

\footnotetext{
${ }^{4}$ Entrevista disponível em https://www.angolapoa.com.br/. Acesso em junho de 2020.

${ }^{5}$ Esta possibilidade foi inspirada em experiências já realizadas por outros autores, como Carvalho et al (2020).
} 
leu o texto, que transcrevemos na próxima seção. A partir disso, concluímos a nossa descrição mobilizados pela ideia de "transversalidade criativa" proposta pelo dossiê da Revista Mundaú, tomando-a não apenas para pensar os encontros realizados durante a disciplina, mas a estendendo para a composição do texto. Finalmente, o texto foi enviado para aprovação do mestre e os últimos ajustes foram realizados.

\title{
SOBRE A MINHA PARTICIPAÇÃO NO ENCONTRO DE SABERES DA UFRGS 2018/2 (MESTRE CHURRASCO)
}

\author{
Assunto: história da capoeira em vários aspectos \\ Público: estudantes de diversas áreas do saber universitário da UFRGS
}

A minha atividade no Encontro de Saberes da UFRGS começou com a influência do aluno da faculdade Marco, da antropologia, e estudante de capoeira do grupo Áfricanamente. Ele me falou sobre o interesse da Universidade em ouvir alguns mestres da cultura popular de diversas linhas. No meu caso, tratei sobre o assunto capoeira e suas influências.

Esta disciplina Encontro de Saberes nas universidades do Brasil teve início em Brasília, pelo professor José Jorge de Carvalho. No Rio Grande do Sul, fui o ministrante da matéria capoeira.

Os encontros foram organizados por uma equipe de professores e estudantes da capoeira. Foi muito bom para me orientar sobre a universidade e alguma organização necessária para o trabalho que eu desenvolvi dentro da área. O Marco esteve sempre presente, assim como o Julio.

Devido à minha formação, que é primária, no começo me senti um pouco constrangido em falar para um público universitário, sendo que nunca tinha tratado da minha atividade dentro de uma universidade. Mas me desdobrei no saber dos velhos mestres que me passaram a forte história da nossa arte. Sendo o meu primeiro mestre o senhor Henry Cal, pioneiro da capoeira no estado do Rio Grande do Sul, fundamentei-me nas fontes do conhecimento da capoeira.

Iniciei a minha experiência em transmitir o nosso saber no primeiro encontro, dentro de certa base do que estudaríamos nas aulas vindouras. Trabalhei do termo "capoeira" à roda de capoeira. Tratamos sobre assuntos da história da capoeira no Brasil inteiro. Começamos no tempo do Império até o século XXI, e tratamos da capoeira da senzala à universidade. Seguimos com o assunto "berimbau", o primeiro instrumento da capoeira, e o que eu mais me dedico, no que tenho o título de "berimbauzeiro", devido à criatividade dos berimbaus de diversas formas jamais vistos, como o "birimbau" (com dois arames), o 
tririmbau (de três arames), e vários outros ${ }^{6}$. Tratei também sobre o arco musical na África, antes de chegar ao Brasil, e a sua influência na capoeira. Foi um trabalho com o berimbau e outros instrumentos utilizados dentro da capoeira, como o pandeiro, caxixi, etc. Dentro da área do arco musical, fizemos um trabalho ao ar livre, no pátio do Planetário, e também fizemos um trabalho no mato para o conhecimento de várias madeiras usadas no arco musical. Foi pensado em relação com a botânica, porque tratamos sobre o assunto de como tratar a casca e o aproveitamento da parte medicinal das folhas como infusão, que é da medicina capoeirística. Falamos da situação dos velhos mestres e mestras que iniciaram o saber da capoeira. Tratamos mais sobre a capoeira angola e também sobre a capoeira regional, sobre os estilos da capoeira, e também tratamos de outras lutas infiltradas na capoeira moderna.

Além da atividade em sala de aula, tive a oportunidade de mostrar ao ar livre movimentos básicos da capoeira para estudantes e professores de várias idades e também tivemos uma atividade de canto. As cantigas de capoeira foram tratadas nos seus temas e seus fundamentos.

Como base para a pesquisa, trabalhei com o livro Capoeira Angola: Ensaio Socioetnográfico, de Waldeloir Rego, que é um estudo de velhos mestres e seus fundamentos e atividades de base para os estudantes de capoeira.

No decorrer da atividade do Encontro de Saberes tivemos a oportunidade de conhecer outras personalidades da capoeira e outros mestres do saber popular, como o cacique Kaingang João Padilha e a Mestra Iracema Rã-Nga Nascimento (Morro Santana, Porto Alegre, RS) e a Rainha Ginga do Maçambique Mestra Preta, Francisca Dias (Osório, RS).

Após trabalhar o tema "capoeira" em diversos aspectos como história, música, meioambiente, botânica e outros assuntos já citados, foi concluída a minha atividade do Encontro de Saberes da UFRGS com uma roda de capoeira com fortíssimas características da capoeira angola, no padrão do Rio Grande do Sul, onde todos se reuniram com o objetivo de absorver o saber que emanava das cordas do berimbau e as virtuosas letras das ladainhas cantadas pelos mestres presentes nesta roda dos tempos modernos. Pois no passado, as rodas de capoeira eram realizadas em frente a botequins, quitandas, feiras, festas de largo e Cais do Porto, e outros ambientes das classes populares, no lugar de pessoas do povo e com difícil acesso à educação. Mas, no nosso tempo, a capoeira já está tendo também sua conquista, pelo constante esforço dos velhos mestres do passado, que mesmo sob a profunda repressão souberam transmitir os seus saberes pela tradição da oralidade, que hoje está

\footnotetext{
6 Vídeo de apresentação destes instrumentos em https://www.youtube.com/watch?v=eeenKPO3CE0. Acesso em junho de 2020.
} 
despertando o interesse de várias classes sociais e culturais, assim como as universidades, escolas, quartéis, hospitais, etc, devido à variedade de recursos que ela traz à tona. Esta arte contém recursos ainda desconhecidos por muitos capoeiras.

Mas voltando àquela "roda de saberes", as pessoas que por ali estiveram, em sua grande maioria eram estudantes, professores e outros frequentadores da universidade que por ali transitavam, tiveram a oportunidade de vivenciar os belos movimentos descritos pelos habilidosos capoeiras que no centro da roda quase flutuavam ao som de berimbau, pandeiro, atabaque, caxixi e reco-reco, que formavam no ar uma energia benéfica que os sensibilizava, deixando aquela expressão no rosto de alegria, concentração, atenção e estudo. Sendo que muitos dos atos capoeirísticos eram somente compreendidos pelos capoeiristas iniciados ou mais adiantados, mas despertando a consciência emocional e também física de muitos que ali estavam, que sutilmente transparecia a sua vontade de saber mais sobre aquele estranho bailado guerгеiго.

Fiz um esforço para transmitir no diálogo corporal com Mestre Cobra Mansa, um grande capoeirista de renome internacional e valoroso estudante dos fundamentos da capoeira, vindo de uma base popular, hoje pessoa no nível acadêmico mas fortemente ligado às tradições populares, com o qual demonstramos um ótimo jogo, depois de mais de 30 anos que não nos víamos. Tínhamos também presente outro grande capoeirista acadêmico da área da educação física, Mestre Ratinho, e ótimo jogador, bom também de assuntos relacionados com as matérias de estudos capoeirísticos, que tem trabalho no estado do Rio Grande do Sul. Também presente Mestre Guto, do grupo Áfricanamente, além de outros capoeiristas que ali estiveram e fizeram parte da democrática roda, como Cássio, Marco e mulheres habilidosas, como Magnólia, Brenda e Jane. Todos com o mesmo objetivo, a busca de um saber que ainda não é acadêmico, mas é saber vivo que temos transmitido de geração em geração até os dias de hoje, em que a capoeira está em mais de 180 países, jogada por todas as classes sociais, independente de sexo e religião. Tivemos um fechamento com chave de ouro para a história da capoeira gaúcha.

Pela primeira vez, como um mestre do povo, com apenas a noção básica do ensino fundamental, tive a oportunidade de levar um pouco do meu conhecimento, que fui iniciado pelo meu grande Mestre Cal, na década de 1970, como também passei por outros grandes mestres que me permitiram continuar o meu saber, como Mestre Vadinho, Roque Pitú, no Rio de Janeiro, Bentinho (RJ), Sandrinha (RJ), João Grande (BA), João Pequeno (BA), Moraes (BA), Cláudio de Roto (RJ), Paulo dos Anjos (BA), Ritinha (BA), assim como a convivência com grandes mestres que passaram pelo Rio Grande do Sul, como Mestre Índio, Mestre Monsueto, Mestre Cerqueira, Mestre Miguel, Mestre Nô, Mestre Ferro Velho, Mestre Paulinho Mato Grosso, e os baianos, com os quais formei o meu baú de saber, que eu pude 
humildemente transmitir aos universitários. Quem ganha é a capoeira e os mestres que me ensinaram. Sou um discípulo que aprendo e mestre que dou lição.

A partir desta atividade na UFRGS fui chamado a outras universidades, em Rio Grande (FURG) e Montenegro (UERGS). Devido à pandemia, o trabalho do capoeira está parado, mas o capoeira não para, pois ele é como um fluido que se desmancha em um lado e se transforma em outro.

Agradeço a todos, desde o reitor da universidade ao fundador da matéria do Encontro de Saberes, às professoras e aos professores da disciplina e alunos e pessoas presentes, e a Deus, principalmente.

Porto Alegre, 25 de Julho de 2020.

\section{ACOMPANHANdO O ENCONTRO (MARCO E JULIO)}

Ainda que a proposta de acompanhar Mestre Churrasco durante a disciplina tenha sido muito empolgante para nós dois, ela também nos parecia carregada de desafios. Desde nossas primeiras conversas, que alimentavam uma grande expectativa ante esse momento singular, o que mais nos preocupava eram os termos nos quais se daria esse encontro. Essa questão foi formulada pelo professor José Carlos dos Anjos na aula introdutória ao módulo da disciplina dedicado aos encontros com Mestre Churrasco. Na ocasião, o professor chamou a atenção para a necessidade de uma real abertura para o encontro com este saber, que pode ser considerado uma expressão política de luta e resistência contra os processos de opressão. Caso essa abertura não ocorresse efetivamentte, o encontro correria o risco de ocorrer sob os termos de um conhecimento acadêmico historicamente ancorado na desqualificação do saberes populares que fundamentam a própria existência da disciplina Encontro de Saberes.

Essa forma de se relacionar com a diferença sem submetê-la está presente em diversas expressões culturais de matriz africana, como na filosofia política dos povos de terreiro de "linha cruzada" estudados por Anjos (2006); no pensamento quilombola de Antonio Bispo Santos (2015), indicado na bibliografia da disciplina, o qual preza pela "confluência" entre os saberes, por oposição à influência; ou na própria capoeira. Na filosofia da diferença da capoeira o dentro e o fora tendem a se confundir, quando o que se busca é o envolvimento e a atração do contrário a um ponto que o deixe vulnerável ao impacto ou à queda, o que pode ocorrer efetivamente ou ser "marcado" com a explicitação dessa possibilidade (SODRÉ, 1988, p. 203). Assim, seria possível que esse Encontro de Saberes funcionasse nesses termos, como uma ardilosa sedução, ou as frias taxonomias universitárias acabariam se impondo para apresentar as performances do Mestre dentro de uma sala de 
aula como em um museu vivo, como mais um exótico evento cultural com o que completar uma grande enciclopédia dos saberes populares do Brasil? Encontro: jogo ou captura?

Após várias reuniões e conversas, a participação do Mestre Churrasco no Encontro de Saberes aconteceu no segundo semestre daquele ano. Vale salientar a cálida articulação propiciada pela professora Ana Lúcia Tettamanzy, que desde o primeiro encontro mostrou bastante afinidade com o Mestre Churrasco. Esse ano, além da Ana Lúcia, do Instituto de Letras, atuaram na disciplina os professores Marília Raquel Albornoz Stein, Celina Nunes Alcântara e Luciana Prass (Instituto de Artes - IA), Rumi Regina Kubo (Faculdade de Ciências Econômicas - FCE), José Carlos dos Anjos e José Otávio Catafesto de Souza (Instituto de Filosofia e Ciências Humanas - IFCH), aos quais agradecemos a oportunidade de participar no projeto. Certamente, a sensibilidade deles foi determinante para o feliz andamento do Encontro de Saberes na UFRGS. A turma era formada principalmente por estudantes do curso de Música, ao qual a disciplina é vinculada institucionalmente, mas também participaram estudantes de História, Comunicação e outros cursos. Em sua maioria brancos, apenas alguns poucos relataram ter experiência prévia com a capoeira. Nesse contexto, nossa função foi acompanhar o Mestre e, na medida do possível, auxiliar na sua relação com os estudantes e os professores, sobretudo fora do contexto da sala de aula, encontrando o mestre antecipadamente, agendando as atividades etc.

Mestre Churrasco conduziu quatro encontros: no primeiro dia da disciplina, ele apenas devia passar na sala de eventos do Planetário, local dos encontros, para se apresentar e cumprimentar a turma, mas terminou ocupando todo o tempo restante da aula com sua fala e toques de berimbau. No segundo encontro foi exibido o depoimento do mestre para o projeto Angola Poa, acima referido, seguido de uma longa conversa. O terceiro encontro ocorreu em um mato no Campus do Vale, onde se movimentaram os corpos e se conversou sobre madeiras e plantas. No quarto encontro, de volta na sala do Planetário, o Mestre prosseguiu contando histórias da capoeira e de sua própria vivência, e depois todos saímos ao pátio para práticas de musicalidade com berimbaus, palmas, pandeiros e canto. Finalmente, no último dia da disciplina, foi realizada uma roda de capoeira angola sob coordenação do Mestre Churrasco, no Campus Centro da UFRGS. Organizamos nossa descrição em cinco tópicos, que de diferentes maneiras foram eixos de significação daquele acontecimento: o planetário, o mato, o livro, a roda e o berimbau.

\section{O PlanetáRIO}

O interior de um espaço escuro, hermético e convexo, concebido para observar o cosmos. Por que as aulas do Encontro de Saberes acontecem no Planetário? No primeiro dia da disciplina, as professoras deram uma breve explicação sobre questões burocráticas, algum 
assunto relacionado com a disponibilidade de espaços para uma disciplina que está lotada no Instituto de Artes, mas aberta para toda a comunidade acadêmica, e sobre a proximidade com a sala do Núcleo de Estudos Afrobrasileiros (NEAB), no mesmo prédio. Localizado na transitada Avenida Ipiranga, em uma região central de Porto Alegre, o Planetário está dentro do cercado da Faculdade de Comunicação, próximo ao Campus da Saúde. Mas pela sua peculiar arquitetura e seu posicionamento afastado dos outros prédios, terminou ganhando uma personalidade própria na paisagem urbana, como um enclave conhecido para além dos circuitos universitários. Por exemplo, ele dá o nome popular de uma comunidade próxima, mais conhecida como "Vila Planetário" que por seu nome oficial.

Quando informamos ao Mestre Churrasco que lá aconteciam os encontros, ele se mostrou muito interessado em conhecer o local. No primeiro dia, fez questão de nos encontrar uma hora antes da aula para observar as instalações. O mestre trazia no ombro, como de costume, alguns berimbaus que confecciona para vender. Eram berimbaus coloridos, realizados com cabaças em forma de cuia (utilizando para a confecção dos instrumentos a mesma parte das cabaças que são utilizadas para fazer as cuias de chimarrão no Rio Grande do Sul), o que confere aos seus berimbaus uma estética e sonoridade muito particular. Ainda que o prédio seja aberto à visitação com agendamento prévio, todo o recinto é cercado e tem guardas na guarita de entrada. Chegando juntos, explicamos que participaríamos da disciplina e o acesso foi liberado sem muitas perguntas. Já dentro do Planetário, o Mestre olhava com atenção as maquetas do sistema solar e os painéis sobre os ciclos da lua e outros corpos celestes. Enquanto aguardávamos a chegada da turma, ia olhando e comentando a influência dos ciclos lunares na vida das pessoas e na prática da capoeira, insistindo na importância da conexão circular entre a terra e o céu. Esses temas foram aparecendo mais tarde nas aulas que conduziu, por exemplo, quando lembrou a cantiga: "Lá no céu tem três estrelas / todas três em carreirinha / uma é minha, outra é tua / a outra vai ficar sozinha". A partir dessa cantiga, Mestre Churrasco apresentou a sua compreensão da capoeira não como uma disciplina ou conhecimento específico, mas como uma perspectiva a partir da qual acessar qualquer outro saber. Assim, se é preciso um pedaço de pau pra fazer uma baqueta, vai ter que aprender sobre madeiras, árvores, climas e matos; se escuta a cantiga das "três estrelas" e quer entender seu significado, vai ter que estudar sobre astronomia, mas também interpretar o simbolismo que liga essa constelação em específico com a capoeira. E o Mestre continuava explicando sobre a dualidade das estrelas "tua / minha" como o jogo de contrários e a terceira como vértice de equilíbrio, o tocador do berimbau: "então, esse conhecimento das estrelas já é da capoeira, já é estudo da capoeira".

Nesse primeiro dia, quando finalmente a turma se reuniu no salão, as professoras pretendiam dedicar o encontro a explicar o cronograma da disciplina, apresentar os mestres que iam participar e explicar o trabalho final que os estudantes deveriam entregar para ser 
avaliados. Segundo a planificação do curso, nesse dia Mestre Churrasco deveria realizar apenas uma breve apresentação, com cerca de quinze minutos. Porém, assim que o Mestre começou a falar, ele foi costurando um intricado discurso no que sua biografia se entrelaçava com a história da capoeira, desde a escravidão no Brasil Colônia e as fugas aos Quilombos até a capoeira contemporânea em academias e ginásios, desde o trem no qual embarcou quando jovem rumo ao Rio de Janeiro até a história das maltas e a perseguição dos terreiros. As professoras souberam aproveitar esse momento descontraído, permitindo que a sua narrativa tomasse o restante da aula sem interrompê-lo e provocando-o a mostrar e tocar os berimbaus que trazia consigo, o que fez com grande habilidade, explorando as sonoridades dos instrumentos de formas pouco convencionais, o que encantou a turma e despertou o interesse de alguns estudantes em adquiri-los ao final do encontro.

Nessa fala, em um dos seus primeiros comentários, agradecendo o convite, o mestre expressou a sua felicidade por estar lá e disse estranhar a facilidade com que conseguiu entrar no recinto, sem precisar apresentar nenhuma informação, crachá nem documento. Contou que a universidade era um mundo que sempre the foi negado, desde criança, quando olhava admirado para os prédios da UFRGS, especialmente esse chamativo Planetário, e foi advertido de que aquele não era lugar para ele, pois destinava-se a pessoas ricas. A entrada no Planetário, para o Mestre, foi uma entrada na Universidade, mas suas palavras e berimbaus transformaram o espaço até então considerado alheio. Após outras duas aulas conduzidas pelo Mestre nesse mesmo local, era notável a comodidade com a qual circulava pelos espaços circundantes do Planetário, ainda que não estivesse de todo livre dos olhares de estranhamento. Essa territorialização teve um momento alto no quarto encontro, quando Mestre Churrasco conduziu os exercícios de musicalidade no pátio do Planetário, um jardim com gramado e árvores floridas. Lá organizou a turma em roda e distribuiu instrumentos, numa grande brincadeira de toque e canto, visível desde a rua para qualquer passante.

Para os estudantes, esse deslocamento até o Planetário pode ter provocado um interessante estranhamento. Mesmo que formalmente não fosse uma saída da Universidade, todos os alunos que participaram na disciplina estavam fora do seu ambiente rotineiro nesse local, onde normalmente não acontecem aulas. Esse pequeno deslocamento pode ser um facilitador da desestabilização que propiciam as aulas do Encontro de Saberes, desinibindoos para as atividades propostas. Se a proposta não é tanto o acúmulo de mais um conhecimento normal, mas a ruptura e revisão de aprendizados prévios, esse deslocamento e desinibição podem ter sido facilitadores. Não sabemos até que ponto a escolha do local foi premeditada, mas certamente resultou num território produtivo.

\section{O МАто}


O terceiro encontro ocorreu em um mato, no Campus do Vale. É uma dinâmica habitual que algum dos encontros conduzidos pelos convidados no Encontro de Saberes aconteça em algum lugar fora da Universidade, e o mestre escolheu realizar esta vivência no mato, uma prática que costuma fazer eventualmente com seus alunos, pois é no mato que o mestre gosta de treinar. "Capoeira na capoeira", como diz Mestre Churrasco, com base em uma das possíveis etimologias para o termo capoeira, que o aponta com o significado de "mato ralo" (IPHAN, 2007, p. 12).

Nos primeiros encontros no salão do Planetário, alguns alunos capoeiristas já tinham perguntado sobre esses treinos que o Mestre conduzia nos matos do Morro Santana, pois já tinham ouvido falar. Ele explicava a importância desse espaço para o seu entendimento da capoeira, mas ao mesmo tempo alertava para as dificuldades e perigos desse ambiente. Disse que há mais de trinta anos que tem esse costume de treinar no mato. No início ia até lá para buscar madeiras, cipós e sementes, e estando lá começou a treinar como quem não quer nada, "dava umas pernadinhas para um lado e para o outro, e me sentia bem. E depois via uma baita de uma pedrona, e pensava, vou subir, sentar um pouquinho, será que dá para gingar aqui?". Na aproximação lúdica aos elementos desse espaço rugoso e instável, entendeu que poderia brincar com galhos e rochas tentando se equilibrar, entrar em troncos ocos, balançar-se nos cipós, enfim, aprender as coisas que a natureza ensina: "Tem uma folha lá no alto? Vou tentar mexer ela apenas com o vento do pé. Tem uns passarinhos cantando? Já pego o berimbau e vou tocar com esses caras". E explicava por que essa ligação com o mato é tão fundamental para a capoeira: "Pensando na época dos Quilombos, pra ir pro mato, tinha que se aprimorar na capoeira. Eram uns terrenos complicados, e às vezes não tinham nem calçado, em terreno cheio de espinhos". Por isso alertava: "não ache que a natureza é barbada não, o mato é perigoso!". O mestre avisava que era necessário saber entrar nesse terreno, entidade viva que não é nossa, respeitando seus habitantes sem levar energia negativa para si mesmo nem para os outros. Dentre os perigos, mencionou aranhas, cobras e espinhos, e também a violência e o estranhamento que poderíamos criar no Morro se chegássemos com um grupo tão grande. Por isso, disse, é importante escolher o local certo, e o mato no Campus do Vale the pareceu adequado.

No dia combinado, marcamos um ponto de encontro em uma parada de ônibus e caminhamos seguindo o mestre. Ao chegarmos no local, Mestre Churrasco solicitou aos alunos que se espalhassem e escolhessem algum lugar para ficar: no chão, em cima das pedras, na descida, entre ou em cima das árvores, e começou a passar movimentos básicos de capoeira, que deveriam ser feitos onde cada um se encontrava. Não somente os alunos, mas também os professores participaram da atividade. Visivelmente, o mestre estava muito mais à vontade do que na aula anterior, no espaço fechado de uma sala de aula, onde passou a maior parte do tempo sentado. Tratava-se de uma experiência corporal, e não somente 
pelo local onde se realizava, a maneira do mestre conduzir a aula foi diferente de todas as vivências de capoeira que já participamos com outros mestres. Рara uma turma de novatos, geralmente se ensina os passos da "ginga" (movimento básico da capoeira) e alguns movimentos básicos que devem ser repetidos. Nesta ocasião, o mestre mostrava vários golpes encadeados, trabalhando muito mais com possibilidades e noções de jogo do que repetições. Uma aula bastante dinâmica, corporalmente desafiadora e lúdica, como geralmente são as vivências que realiza.

Ao final da tarde foi realizada ainda uma roda de capoeira com a turma, onde todos os participantes foram convidados a tocar os instrumentos e entrar na roda para jogar, o que foi facilitado pelo fato de haver capoeiristas entre os participantes dessa vivência (alunos da disciplina e convidados). Sua idade, que ultrapassa os 60 anos, não impediu que Mestre Churrasco, que já havia feito os movimentos junto com a turma durante a tarde, jogasse com quase todos os presentes.

Antonio Bispo Santos realiza uma interessante comparação das manifestações culturais dos "povos afro-pindorâmicos pagãos politeístas" e dos "povos eurocristãos monoteístas" (2015, p. 41). Mesmo que a descrição do autor seja bastante generalizadora, parece impossível não reconhecer a atividade realizada com o mestre nas linhas que seguem:

\begin{abstract}
"As manifestações culturais dos povos afro-pindorâmicos pagãos politeístas são organizadas geralmente em estruturas circulares com participantes de ambos os sexos, de diversas faixas etárias e número ilimitado de participantes. As atividades são organizadas por fundamentos e princípios filosóficos comunitários que são verdadeiros ensinamentos de vida. É por isso que no lugar dos juízes, temos as mestras e os mestres na condução dessas atividades. As pessoas que assistem, ao invés de torcerem, podem participar das mais diversas maneiras e no final a manifestação é a grande vencedora, porque se desenvolveu de forma integrada, do individual para o coletivo (onde as ações e atividades desenvolvidas por cada pessoa são uma expressão das tradições de vida e de sabedoria da comunidade). [...] Numa roda de capoeira, regida pelos ensinamentos de vida, podemos ter cinquenta pessoas jogando, uma pessoa ensinando e pouquíssimas assistindo. Entre as poucas pessoas que assistem pode haver alguma que nunca viu a capoeira. No entanto, se esta quiser, ela pode entrar na roda e jogar" (SANTOS, 2015, p. 41-42).
\end{abstract}

Percebemos assim o quanto esta vivência, não obstante sua curta duração e o fato de ser voltada para um público iniciante, expressa muito dos "fundamentos" da capoeira para a relação com a diferença. Na roda que Mestre Churrasco conduziu no mato, entraram e jogaram todas as pessoas que quiseram, mesmo as que nunca tinham praticado capoeira. Aberta para o encontro com estranhos, a roda de capoeira não apresenta rígidos mecanismos de exclusão ou de inclusão condicionada, como os que são habituais no espaço universitário, não precisa ser aprovado em nenhum exame prévio para participar da roda. Certamente há critérios que regulam a participação em algumas rodas de capoeira, mas esses não costumam ser dados a priori, ficando subordinados ao contexto no qual o evento acontece. Essas manifestações são regidas pelo saber que Bispo classifica como orgânico, um saber pautado pela oralidade e em estreita continuidade com a vida cotidiana, que se opõe 
ao saber sintético da academia, regido pela palavra escrita (SANTOS, 2018). Essa oposição geral se faz bastante visível pelo contraste que a vivência junto ao Encontro de Saberes impõe diante das nossas trajetórias acadêmicas, compostas por disciplinas cujos programas ostentam, em sua maioria, longas listas de leitura que dificilmente podem ser vividos ao nível da experiência.

\section{O LIVRO}

Na metade do segundo encontro, Mestre Churrasco tirou um livro da sua bolsa. Poderíamos considerar que o livro é o objeto emblema da ciência moderna, integrando a rotina dos estudos acadêmicos que o Encontro de Saberes pretendia subverter. Ainda que existam muitos livros escritos por capoeiristas e pesquisadores sobre a capoeira, e que os capoeiristas sejam grandes leitores do assunto, a utilização do livro como guia parecia menos intuitiva, porque os ensinamentos mais fundamentais da capoeira costumam ser transmitidos oralmente, de modo orgânico.

Era um livro antigo de capa dura, com uma baqueta como marca-páginas, e nas rugas das folhas se apreciava que era um livro viajado, que já havia sido muito manuseado. Até esse momento, o mestre conduzia uma fala fluida, que parecia se enlaçar suavemente com os temas e histórias que narra na entrevista do projeto Angola Poa, que acabávamos de assistir. A partir do momento em que mostrou o livro, como um corte na sessão, toda a aula passou a ser pautada por esse objeto. O Mestre entregou o volume a um aluno, destacando uma página em particular, e pediu, alegando que estava sem seus óculos, que ele lesse em voz alta um fragmento, o qual passou a comentar sem pressa. O resto do encontro seguiu essa dinâmica, intercalando a leitura de fragmentos do livro, comentários do Mestre e perguntas dos estudantes.

Na sua exposição prévia, Mestre Churrasco contava a sua história de vida como um relato do aprendizado da capoeira. Era uma história de sucessivas descobertas, na qual crianças que trabalhavam como jornaleiros e engraxates iam aprendendo golpes de capoeira como uma brincadeira, pequenas brigas nas quais imitavam as cabeçadas e rasteiras que viam ser realizadas pelos marinheiros no cais e nas ruas do centro histórico de Porto Alegre. Nessa história, Mestre Cal, que o iniciou na capoeira, aparece como uma ruptura. Ele era um mestre inteligente, dizia, um mestre que tinha fundamento e tocava berimbau, e que incentivava os jovens a estudar e buscar conhecimento nas bibliotecas. Depois, Mestre Churrasco falou da sua viagem ao Rio de Janeiro, onde viu pela primeira vez uma roda de capoeira com a bateria musical completa, e mais tarde à Bahia, onde conheceu o renomado Mestre João Grande e outros grandes mestres da capoeira. Descrevendo esse processo de procura e aprendizado, os livros iam aparecendo como mais uma fonte de saber, articulado 
com as viagens e as conversas com mestres mais velhos. Falou da biblioteca de Salvador, que revirou nos dois anos em que morou na Bahia, e da Biblioteca Nacional no Rio de Janeiro, como lembranças prazerosas: "Como é bom ler sobre capoeira!". Contava que era difícil encontrar escritos sobre capoeira, era preciso buscar em livros de folclore, nas cartilhas do Projeto Minerva ou de Câmara Cascudo. Até que achou esse livro que agora nos mostrava, no qual encontrou um impressionante estudo sobre o Berimbau, que apresentou para a turma.

O livro em questão é Capoeira angola: ensaio sócio-etnográfico, de Waldeloir Rego (1968). Trata-se de um livro inaugural em sua abordagem, já referido pelo mestre e por muitos capoeiristas como "a bíblia da capoeira", devido à quantidade de informações que reúne sobre esta prática de modo geral. Ainda que a versão digital do livro seja acessível, a edição impressa é um objeto raro, disputado em sebos pelo Brasil. O primeiro capítulo que o Mestre comentou foi "O Berimbau", no qual destacou o uso religioso que esse arco tem nas religiões afro-cubanas, como um artefato para comunicação com os mortos. Também comentou com detalhe as possíveis etimologias de "berimbau" e "gunga" (como é chamado o berimbau mais grave na capoeira angola), para salientar a origem bantu do instrumento. Mostrando crônicas antigas apresentadas por Rego onde se registra o seu uso, Mestre Churrasco realizava comentários críticos chamando a atenção para os preconceitos racistas dos cronistas coloniais, como quando foi lido um fragmento que cita as crônicas de Henry Koster:

\begin{abstract}
"Henry Koster, quando em viagem pelo nordeste do Brasil, observou essas festas e fez uma síntese descritiva, incluindo alguns instrumentos musicais, dentre eles o berimbau, conforme se vê nesta passagem: - "(...) Um homem ia para o centro da roda e dançava minutos, tomando atitudes lascivas, até que escolhia uma mulher, que avançava, repetindo os meneios não menos indecentes, e esse divertimento durava, às vezes, até o amanhecer" (HENRY KOSTER apud REGO, 1968, p. 71).
\end{abstract}

O comentário irônico do Mestre foi categórico: "é... para quem não conhece, qualquer rebolado é indecente". Na sua interação com o livro, o Mestre amplia e desdobra as informações sobre outros lugares e outros tempos, e dá vida sonora e visual aos trechos escritos, entoando as cantigas transcritas ou mostrando alguns dos movimentos com seu corpo, brincando com os estudantes. A gravidade e seriedade de que se reveste o livro é destituída com momentos cômicos de paródia, relaxando o ritmo da aula. Por exemplo, após pedir a leitura de um fragmento especialmente longo e cheio de palavras difíceis, que fazia com que o estudante se atrapalhasse e respirasse aliviado ao terminar, o Mestre fez uma pausa dramática e pediu que, por favor, repetisse a leitura, provocando a gargalhada geral.

Após os capítulos sobre o berimbau e o canto, o Mestre comentou a seção "Ascensão Social e Cultural da Capoeira", que começa com a seguinte frase: "O capoeira desde o seu aparecimento foi considerado um marginal, um delinqüente, em que a sociedade deveria vigiá-lo e as leis penais enquadrá-lo e puni-lo" (REGO, 1968, p. 291). Essa leitura reorientou a conversa para a história de perseguição da capoeira, interpretando os 
Códigos Penais de 1830 e 1890 como dispositivos de controle colonial do povo negro. Afastando-se da literalidade do livro, Mestre Churrasco levou a conversa para as maltas cariocas e sua instrumentalização pelas elites políticas da República Velha, que ao mesmo tempo em que as perseguiam, impondo a lei, se serviam das suas habilidades marciais para quebrá-la ${ }^{7}$. Рara explicar a linguagem secreta do berimbau, cujos toques são indiscerníveis para os não iniciados, tomou o instrumento e executou o toque conhecido pelo nome de "Cavalaria", explicando como esse toque era utilizado para avisar da chegada das forças repressivas, de forma que os capoeiras tivessem tempo de fugir ou dissimular. A aula terminou com essa brincadeira, o Mestre mostrando toques com o berimbau e desafiando os capoeiristas presentes a reconhecê-los.

Na sua aula, Mestre Churrasco colocou esse livro na roda, entre berimbaus, caxixis, conversas e movimentos de capoeira, mostrando como esse objeto pode ser muito interessante se incorporado na gramática do jogo. A conversa com o livro também serviu para expor de que forma, ao longo da história do Brasil, a escrita e o ensino formal funcionaram como mecanismos de exclusão e controle do povo negro. Como ele disse, na sua infância e juventude the foi negado o acesso ao ensino formal, porque desde muito cedo começou a trabalhar. Ainda que isso não o tenha impedido de buscar conhecimento em livros e bibliotecas, essa distância dos documentos e processos burocráticos implicou mais dificuldades e desafios com a administração no momento em que quis formalizar seu grupo de capoeira para poder dar aulas e acessar alguns recursos. O Mestre foi vencendo essas barreiras de papel, conseguindo os requeridos registros e diplomas na Fundação de Educação Social Comunitária, a Federação Gaúcha de Luta Livre e os Ministérios e Secretarias. Nesse dia, repetiu várias vezes que "a estrutura social da capoeira mudou": passou das senzalas e quilombos para as periferias suburbanas e depois aos centros comunitários e projetos sociais, até escolas e universidades. Na aula de Mestre Churrasco, o livro e o berimbau se aproximam, mas no ritmo marcado pelo toque do segundo.

\section{A RODA}

No último dia da disciplina, após a apresentação dos trabalhos finais, foi realizada uma roda de capoeira angola sob coordenação do Mestre Churrasco. A atividade ocorreu no Campus Centro da UFRGS, próximo à Faculdade de Educação. A nós, coube organizar e divulgar a realização do evento. Assim, após combinar com Mestre Churrasco, convidamos os colegas da Áfricanamente Escola de Capoeira Angola, grupo onde Marco pratica capoeira

\footnotetext{
${ }^{7}$ Ver Soares (1994).
} 
desde 2010, e combinamos com o Mestre Guto ${ }^{8}$, líder do grupo, para que levassem os instrumentos para compor a bateria musical. Foi feito ainda um cartaz para divulgação na internet que circulou bastante entre os capoeiristas nas redes sociais. Também foi convidado para a roda o Mestre Cobra Mansa, renomado mestre da capoeira angola, que estava em Porto Alegre participando de uma atividade promovida pelo Ponto de Cultura Áfricanamente em parceria com o GEAfro - Grupo de Estudos Afro, vinculado ao Núcleo de Estudos Afrobrasileiros da UFRGS (atividade que Mestre Churrasco também participou), o qual aceitou prontamente ${ }^{9}$. Mestre Ratinho, outra grande referência da capoeira angola gaúcha, também esteve presente e ajudou a organizar a atividade ${ }^{10}$.

A roda estava marcada para às 17h30min. Já se aproximava do horário e Mestre Churrasco não havia chegado. Capoeiristas de vários grupos foram chegando para a roda e o mestre estava incomunicável. Seu atraso ou mesmo o não comparecimento a algumas atividades de capoeira não é raro, o que também deixou os capoeiristas apreensivos. Próximo às 18h, após conversar com as professoras responsáveis pela disciplina e os mestres presentes, optou-se por iniciar a roda. Marco pediu orientação ao Mestre Guto para ver quem tocaria o Gunga - o berimbau mais grave, a cujo tocador cabe a coordenação da roda -, que orientou oferecê-lo aos mestres mais velhos presentes; Mestre Cobra Mansa argumentou que estava lá como convidado e Mestre Ratinho, que é da região e conhecia melhor os capoeiristas, aceitou conduzir a roda até a chegada do Mestre Churrasco. Uma ética da capoeira era expressa por estes mestres, que queriam evitar assumir o lugar que caberia a Mestre Churrasco. Mestre Cobra Mansa abriu então a roda jogando com vários capoeiristas, para um público encantado com a sua habilidade. Essa era uma roda pública de capoeira angola e seguiu todos os preceitos rituais que geralmente se costuma seguir nesse tipo de roda. Diferentemente da roda realizada no mato, a quase totalidade daqueles que entraram na roda pra jogar nesse dia eram capoeiristas, mesmo que não tenha havido qualquer deliberação nesse sentido. Após alguns jogos, Mestre Churrasco chegou, para alegria geral. Na verdade, é uma característica sua surgir nas rodas de forma repentina. Vinha vestido com uma camisa listrada, colete amarelo, calça social e sapatos brancos, lembrando o traje dos "capoeiras" de antigamente. Trazia nas costas um lindo berimbau, que logo se

\footnotetext{
${ }^{8}$ Sobre Mestre Guto, ver: https://www.youtube.com/watch?v=PJSyagXHDk8.

${ }^{9}$ Mestre Cobra Mansa é natural do Rio de Janeiro e vive atualmente na cidade de Valença, na Bahia, onde fundou o Kilombo Tenondé, espaço no qual realiza trabalhos e pesquisas sobre capoeira angola e permacultura. Contribuiu para a consolidação da capoeira angola no Brasil e no exterior e atualmente é um dos mestres mais famosos da capoeira angola, e percorre o mundo ministrando palestras e oficinas.
}

${ }^{10}$ Sobre Mestre Ratinho, ver: https://www.youtube.com/watch?v=ScywtvLSxql. 
notava ser uma de suas criações. O berimbau possuía uma verga muito grossa de cor azul celeste - que somente quem teve a oportunidade de tocá-lo percebeu que era também muito leve - com pinturas de capoeiristas jogando, detalhes em dourado, e o seu nome na vertical. A cabaça era dupla, com caxixis em miniatura acoplados, algo bastante inusitado para quem nunca teve contato com as suas invenções. Mestre Ratinho interrompeu a roda para anunciar a sua chegada, que foi aplaudida com entusiasmo. Certamente, todos os capoeiristas esperavam ver o jogo de Mestre Churrasco com Mestre Cobra Mansa, e a possibilidade de que isso acontecesse também os animava neste momento. O mestre cumprimentou o público e orientou que a roda continuasse normalmente enquanto ele armava o seu berimbau para ser tocado.

Não tardou para que ocorresse o esperado jogo com Mestre Cobra Mansa, em um clima festivo e muito amistoso. Ao pé do berimbau, Mestre Churrasco cantou uma ladainha que falava da escravidão. Seu canto não apenas rememorava um tempo passado que estaria na origem da capoeira, mas situava a escravidão como extensiva ao seu próprio corpo, gesticulando com o canto: meu corpo marcado do açoite / meu rosto cheio de agonia / eu rezo a meus antepassados... Na sequência, cantou um corrido que homenageava o seu parceiro de jogo (o camarada, o que ele é meu? / é meu irmão...) e, após "passar" o canto para Mestre Ratinho, o jogo teve início. Este foi, conforme comentou Mestre Churrasco posteriormente, um reencontro ao pé do berimbau passados cerca de trinta anos da primeira vez em que jogaram capoeira juntos, em Salvador. Muitos elementos da filosofia da capoeira que Mestre Churrasco comentou nas aulas podiam ser notados na roda, embora estes muitas vezes demandem um olhar mais sensível para que sejam percebidos. Em um dos encontros, por exemplo, Mestre Churrasco demonstrou que muito da malícia do capoeirista se expressa quando este apenas "marca" alguns golpes no jogo de forma bastante sutil, sem a necessidade de aplicá-los efetivamente, apenas mostrando a vulnerabilidade do seu parceiro. Em um jogo entre dois mestres muito experientes, ambos com um estilo de jogo bastante dinâmico, este tipo de situação foi recorrente.

Mestre Churrasco também tocou berimbau e cantou, mas não interferiu muito na roda, ficou assistindo e conversando com algumas pessoas uma boa parte do tempo. Esta também é uma forma de coordenar uma roda de capoeira, deixando-a rolar enquanto tudo ocorre dentro do esperado, sobretudo quando se tem a presença de mestres experientes conduzindo-a. Mestre Churrasco é unânime entre os capoeiristas de Porto Alegre, e do Rio Grande do Sul, pela sua notória sabedoria. E é sabido também que, mesmo tendo realizado trabalhos sociais muito importantes em Porto Alegre, muitas vezes por conta própria, não goza de uma situação financeira tranquila, como mereceria. Assim, certamente muitos dos capoeiristas que foram prestigiá-lo orgulhavam-se de vê-lo naquela atividade de 
encerramento do Encontro de Saberes, percebendo na iniciativa o reconhecimento e valorização do mestre.

Ao final da roda, Mestre Churrasco agradeceu aos presentes e aos professores responsáveis pela disciplina, elogiando a iniciativa que, conforme argumentou, abre a possibilidade de mestres da cultura popular trazer o seu conhecimento para dentro da universidade. A seguir, falou brevemente como foi sua busca por conhecimento, em uma época em que esta impunha muito mais barreiras, para que hoje pudesse compartilhar um pouco com a turma, acrescentando que o aprendizado foi também muito grande ao longo dessa experiência. Em seguida, foi a vez de Mestre Ratinho agradecer e parabenizar os responsáveis pela disciplina, afirmando que este tipo de iniciativa é uma forma de trazer o conhecimento da cultura popular para dentro da universidade, ressaltando ainda a necessidade da capoeira estar sempre junto aos grupos oprimidos e periféricos. Mestre Ratinho observou que ações como essas ainda são pontuais e somente se tornam possíveis pelo esforço de professores interessados nesse diálogo. A sua fala converge com a sua própria trajetória de mestre de capoeira e professor universitário.

O último mestre a falar foi o Mestre Cobra Mansa, que iniciou agradecendo ao Mestre Churrasco pela oportunidade de compartilhar aquele momento. Mestre Cobra Mansa cursava também o quarto ano de doutorado em Difusão do Conhecimento ${ }^{11}$ na Universidade Federal da Bahia e aproveitou a ocasião para fazer críticas contundentes "de dentro" à universidade, cuja estrutura estaria apodrecida, apontando a presença dos mestres da cultura popular como um "sangue novo" para renovar o espaço acadêmico. Sua fala pontuou a necessidade de percebermos, assim, que "na verdade quem tá ganhando é a universidade", uma vez que o saber popular já educa muitas pessoas há muito mais tempo que essas instituições formais. E lembrou que se hoje a capoeira é praticada em quase todos os países, sendo a maior divulgadora da língua portuguesa no mundo, o mérito é todo dos capoeiristas, pois isso foi conquistado sem ajuda governamental. Essa é uma história de dor, luta e sofrimento ("dormindo em carro, passando fome, passando necessidades") e de muita resistência, conforme observou.

Nas últimas décadas a capoeira foi reconhecida como patrimônio cultural imaterial do Brasil (pelo Instituto do Patrimônio Histórico e Artístico Nacional - IPHAN, em 2008) e da Humanidade (pela Organização das Nações Unidas para Educação, Ciência e Cultura UNESCO, em 2014) e muitos capoeiristas são bastante críticos às interpretações que atribuem a instituições governamentais a valorização da sua arte, por isso as palavras do

\footnotetext{
${ }^{11}$ Mestre Cobra Mansa defendeu, em 2019, a tese Gingando na linha da kalunga: a capoeira Angola, Engolo e a construção da ancestralidade (PEÇANHA, 2019).
} 
Mestre Cobra Mansa foram tão importantes naquele momento. Seu apelo parece convergir com as palavras do professor José Carlos dos Anjos na aula de abertura. A atividade encerrou, já durante a noite, com o agradecimento da professora Ana, que se mostrou satisfeita e alinhada ao pensamento dos mestres, afirmando que o objetivo da disciplina é também melhorar a universidade e contribuir para sua descolonização. Ao que Mestre Cobra Mansa concluiu: "é bom a gente saber que tem parceiros lá dentro".

\section{O BERIMBAU}

Mestre Churrasco desenvolveu uma estética muito singular para a sua prática enquanto capoeirista, seja no jogo, na prática musical ou no exercício da oralidade, de modo que a sua versatilidade nas rodas é reconhecida e admirada pela comunidade da capoeira. Mas se algo merece destaque é a ostensiva criatividade com que lança mão na fabricação dos seus berimbaus. Assim, não poderia ser diferente a sua participação no Encontro de Saberes, em que fez questão de levar sempre um berimbau diferente a cada encontro: chamando a atenção de todos desde sua entrada na sala de aula no primeiro dia, conduzindo os corpos no mato, fazendo vibrar o livro e cantar os estudantes no pátio do Planetário, até a sua chegada na roda final despertando a admiração do público com um instrumento tão lindo e característico. O berimbau sempre foi o centro dos olhares e o instrumento guia do mestre.

No primeiro encontro, Mestre Churrasco demonstrou várias possibilidades sonoras dos instrumentos, empolgando a turma, e vários estudantes se aproximaram para testar os arcos musicais. Em geral, quando capoeiristas tem o primeiro contato com o berimbau, cujo peso deve ser sustentado pelo dedo mínimo para ser tocado, a dificuldade maior é sempre equilibrá-lo. Os berimbaus que o mestre levava nesse dia, por serem pequenos e leves, puderam ser tocados mesmo por pessoas que nunca tinham experimentado o instrumento. Nessa primeira experiência, o Mestre incentivou os estudantes a testarem os diferentes sons e brincar com o instrumento, sem se preocupar nesse momento em explicar técnicas complexas ou toques específicos da capoeira. Após desse primeiro dia, foi trazendo, de forma sutil e prazerosa, um conhecimento mais profundo e formalizado do uso do berimbau na capoeira. Com o livro de Waldeloir Rego, foi narrando a presença do berimbau nas tradições bantu, e seu uso continuado nas Américas, em rituais religiosos e em festas populares. Só depois desse preâmbulo explicou como o berimbau foi incorporado na capoeira, para finalmente apresentar a linguagem de toques que um capoeirista deve conhecer, mostrando com o instrumento alguns dos toques básicos: São Bento Grande e São Bento Pequeno, Cavalaria, lúna...

Quando a turma formou uma roda no mato, o Mestre tocou um pouco no início e rapidamente distribuiu vários berimbaus entre os alunos para que seguissem tocando 
enquanto ele jogava, aproveitando-se do conhecimento musical de grande parte da turma para estimulá-los a criar. Era uma roda espontânea e alegre, sem muita preocupação com a dimensão ritual, a disposição da bateria ou a hierarquia dos que tocam e cantam. No fim das contas, alunos que há apenas duas semanas haviam tocado um berimbau pela primeira vez, puderam experimentar a sensação de tocar e cantar enquanto outras pessoas jogavam, tentando articular o diálogo entre sons e movimentos.

Finalmente, os estudantes tiveram a oportunidade de sentir a solenidade de uma roda pública na roda de fechamento da disciplina, com a participação de outros mestres como convidados. A bateria musical formada por tocadores experientes, mestres jogando, a interação do canto com os jogos e demais aspectos rituais que constituem a roda de capoeira angola. Junto com Mestre Churrasco, entram na universidade suas relações com outros grupos e capoeiristas, impondo uma particular forma de relacionar-se: a escolha de quem vai tocar o Gunga, os códigos para entrar e sair da roda, para cantar ou passar a palavra... E a chegada surpreendente de Mestre Churrasco com seu berimbau singular, assinando a mestria de "berimbauzeiro".

Para finalizar, retomamos a questão formulada no início, sobre a política da diferença com a qual se equacionou esse Encontro de Saberes. Devemos novamente ressaltar a sensibilidade dos professores, que souberam balançar as exigências da burocracia acadêmica com a abertura para outras formas de organizar o tempo e os espaços, cedendo efetivamente ao mestre a condução dos encontros. Desde o primeiro momento, ele assumiu essa função e fez do berimbau sua batuta. Mestre Churrasco conduziu esse encontro com a universidade como um jogo de capoeira, envolvendo os estudantes em suas brincadeiras, desestabilizando certezas e embaralhando fronteiras. Não se trata apenas de transmitir conhecimentos ou performatizar saberes. Acompanhá-lo nesses encontros nos fez lembrar a sabedoria dos velhos mestres: "na capoeira, o berimbau é quem ensina". Mais do que ensinar elementos básicos da capoeira, no pouco tempo disponível, seu grande feito parece ter sido conduzir os encontros de modo que os alunos pudessem se entregar ao ritmo da capoeira: criando, arriscando improvisos, sendo estimulados a experimentar outras formas de se relacionar consigo mesmo e com o Outro. A cada participante cabe extrair de um encontro as potências de que é capaz. Pelo entrosamento que a turma demonstrou ao longo da disciplina, acreditamos que o Encontro de Saberes cumpriu o desafio de proporcionar experiências transversais aos diferentes modos de conhecimento em jogo.

Já no primeiro contato realizado com Mestre Churrasco para convidá-lo a participar da disciplina, o mestre manifestou o interesse de aproveitar a proximidade com a universidade para tentar a possibilidade de revelação de antigos negativos fotográficos contendo em sua maioria registros de eventos de capoeira realizados por ele. A partir da 
mediação da professora Ana Tettamanzy junto ao Museu da UFRGS, esses negativos estão sendo revelados e uma exposição com as respectivas fotografias está em fase de produção junto à instituição. Este é um exemplo positivo das novas articulações que podem nascer dos encontros propostos pela disciplina. Por outro lado, como observa Carvalho (2016), alguns entraves burocráticos ainda impedem a remuneração adequada desses mestres, em função das exigências de titulações acadêmicas para que as instituições possam realizá-lo plenamente. Isso faz com que às vezes os professores precisem custear com recursos próprios algumas despesas oriundas da disciplina, como foi o caso do transporte do mestre para Porto Alegre.

Nesses encontros tivemos a oportunidade de constatar mais uma vez o notório saber de Mestre Churrasco, que se destaca em todos os âmbitos da capoeira, incluindo a musicalidade, a movimentação e os conhecimentos históricos e filosóficos. Em outras ocasiões, o Notório Saber de mestres e mestras dos saberes e fazeres tradicionais tem sido reconhecido oficialmente por algumas universidades. Na capoeira, é sintomático que o primeiro título de Doutor Honoris Causa tenha sido fornecido nos Estados Unidos, pela Upsala College, de Nova Jersey, em 1994, ao Mestre João Grande. Somente na última década é que alguns mestres foram agraciados com o título de Doutor Honoris Causa por universidades brasileiras, como os mestres Bimba (in memorian), João Pequeno, Nô e Boca Rica ${ }^{12}$. Nesse sentido, incentivamos às instâncias pertinentes que considerem o nome de Mestre Churrasco para um reconhecimento deste tipo, fazendo coro à demanda de profissionais envolvidos com o projeto Encontro de Saberes (CARVALHO, 2016) para o reconhecimento do Notório Saber dos mestres participantes da disciplina, em direção a uma efetiva e almejada descolonização das nossas instituições de ensino.

\section{REFERÊNCIAS}

ANGOLA POA. Entrevista Mestre Churrasco. Vídeo. 38:16 min. Disponível em: https://www.angolapoa.com.br/mestre-churrasco. Acesso em 29/06/2020.

ANJOS, José Carlos dos. No território da linha cruzada: a cosmopolítica afro-brasileira. Porto Alegre: Ed. UFRGS, 2006.

CARVALHO, José Jorge de. Sobre o notório saber dos mestres tradicionais nas instituições de ensino superior e de pesquisa. Cadernos de Inclusão, nº 8. Brasília: INCTI/UnB, 2016.

\footnotetext{
${ }^{12}$ Recentemente a Universidade Federal de Minas Gerais (UFMG) deu um passo importante nesta direção, através de Resolução do Conselho Universitário que regulamenta o reconhecimento de Notório Saber pela UFMG. Conforme: https://www.saberestradicionais.org/notorio-saber-para-osmestres-e-mestras-dos-povos-e-comunidades-tradicionais-uma-revolucao-no-mundo-academicobrasileiro/
} 
CARVALHO, José Jorge de et al. Sofrimento psíquico na universidade, psicossociologia e Encontro de saberes. Soc. estado., v. 35, n. 1, p. 135-162, 2020.

INCTI - Instituto Nacional de Ciência e Tecnologia de Inclusão no Ensino Superior e na Pesquisa. Encontro de Saberes nas Universidades: bases para um diálogo interepistêmico. (Documento-base do Seminário). Brasília: UnB, 2015.

IPHAN - INSTITUTO DO PATRIMÔNIO HISTÓRICO E ARTÍSTICO NACIONAL. Dossiê. Inventário para registro e salvaguarda da capoeira como patrimônio cultural do Brasil. Ministério da Cultura: Brasília, 2007. Disponível em www.iphan.gov.br.

PEÇANHA, Cinésio Feliciano. Gingando na linha da kalunga. A capoeira Angola, Engolo e a construção da ancestralidade. Tese de doutorado multidisciplinar em difusão do conhecimento - UFBA, 2019.

SANTOS, Antonio Bispo. Colonização, Quilombos: modos e significados. Brasília: INCTI, 2015.

SANTOS, Antonio Bispo. Somos da terra. PISEAGRAMA, n. 12, p. 44-51, 2018. Disponível em <https://piseagrama.org/somos-da-terra/>. Acesso em 29-06-2020.

REGO, Waldeloir. Capoeira angola: ensaio sócio-etnográfico. Salvador: Itapuã, 1968.

SOARES, Carlos Eugênio L. Negregada instituição: os capoeiras no Rio de Janeiro. Coleção Biblioteca Carioca, vol. 31. Rio de Janeiro, Secretaria Municipal de Cultura, 1994.

SODRÉ, Muniz. Capoeira, um jogo de corpo. In: SODRÉ, Muniz. A verdade seduzida. Rio de Janeiro: Francisco Alves, 1988. p. 202-214.

STEIN, M. R. A. et al. A interdisciplina Encontro de Saberes/UFRGS como proposta investigativametodológica. Anais da VII Reunião de Antropologia da Ciência e da Tecnologia, v. 4, p. 1-21, 2019.

Recebido em 02 de setembro de 2020. Aprovado em 01 de fevereiro de 2021. 